Antarctic ice shelf caverns

\title{
A data-constrained model for compatibility check of remotely sensed basal melting with the hydrography in front of Antarctic ice shelves
}

D. Olbers et al.

D. Olbers ${ }^{1}$, H. H. Hellmer ${ }^{1}$, and F. F. J. H. Buck ${ }^{2}$

${ }^{1}$ Alfred Wegener Institute Helmholtz Centre for Polar and Marine Research, Bussestr. 24, 27570 Bremerhaven, Germany

${ }^{2}$ Leibniz-Institute for Baltic Sea Research, 18119 Rostock-Warnemünde, Germany

Received: 19 December 2013 - Accepted: 1 January 2014 - Published: 5 February 2014

Correspondence to: D. Olbers (dirk.olbers@ awi.de)

Published by Copernicus Publications on behalf of the European Geosciences Union.
Title Page

4

Back 


\section{Abstract}

The ice shelf caverns around Antarctica are sources of cold and fresh water which contributes to the formation of Antarctic bottom water and thus to the ventilation of the deep basins of the World Ocean. While a realistic simulation of the cavern circulation

5 requires high resolution, because of the complicated bottom topography and ice shelf morphology, the physics of melting and freezing at the ice shelf base is relatively simple. We have developed an analytically solvable box model of the cavern thermohaline state, using the formulation of melting and freezing as in Olbers and Hellmer (2010). There is high resolution along the cavern's path of the overturning circulation whereas the cross-path resolution is fairly coarse. The circulation in the cavern is prescribed and used as a tuning parameter to constrain the solution by attempting to match observed ranges for outflow temperature and salinity at the ice shelf front as well as of the mean basal melt rate. The method, tested for six Antarctic ice shelves, can be used for a quick estimate of melt/freeze rates and the overturning rate in particular caverns, given the temperature and salinity of the inflow and the above mentioned constrains for outflow and melting. In turn, the model can also be used for testing the compatibility of remotely sensed basal mass loss with observed cavern inflow characteristics.

\section{Introduction}

The physical processes inside ice shelf caverns are still mostly unobservable. As satellite and airborne observations became available, better estimates of the mass budget of the ice lid were possible (Rignot, 1998; Corr et al., 2001; Shepherd et al., 2004; Rignot et al., 2013). Autonomous vehicles have been developed for entering a cavern and measure bathymetric, hydrographic, chemical and turbulence parameters, but the range of such vehicles is very limited and only few expeditions took place so far (Nicholls et al., 2006; Jenkins et al., 2010). Numerical models of various complexity have been developed (Hellmer and Olbers, 1989; Jenkins, 1991; Holland and Jenkins,
TCD

8, 919-951, 2014

Antarctic ice shelf caverns

D. Olbers et al.

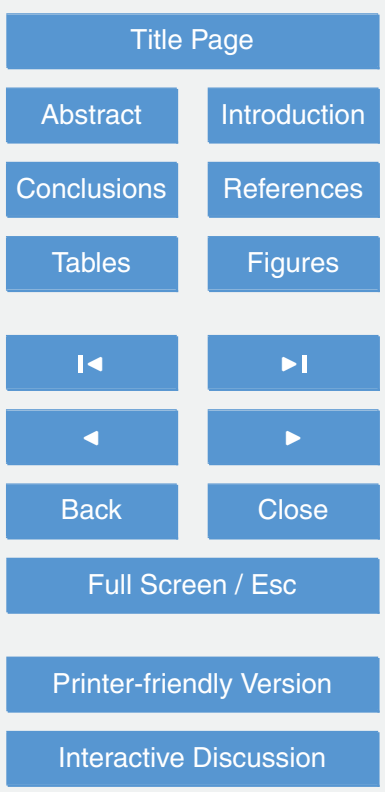

(i) 
1999; Gerdes et al., 1999; Beckmann et al., 1999; Losch, 2008; Timmermann et al., 2012) that are driven by the observed hydrographic characteristics (temperature and salinity) at the ice shelf front or on the boundary of the adjacent ocean part. Such models help putting the scattered information together, but it is by no means evident that 5 the collected knowledge should be consistent with the model output, i.e., that a model driven by observations at the ice front yields the melt rate which is inferred from mass budget calculations. If the model possesses a sufficient scope in terms of the dynamics, thermodynamics and resolution, it is at the same time still too elaborate to scan the space of tuning parameters adequately.

The approach introduced in the present study uses a highly simplified model, allowing for an analytical solution and having hence the potential to scan the complete parameter space and possibly finding a parameter set for which the solution agrees with the observations (within a reasonable range of uncertainties) available for a particular cavern. The model aims to describe the overturning in a cross-cavern integrated sense, the balances of heat and salt are solved analytically for a steady state, assuming a given overturning rate and pattern; there are thus no dynamics considered. The model simply transfers the thermohaline inflow conditions and the coupling to the heat and freshwater exchanges at the ice shelf/ocean interface into the outflow conditions. The melting/freezing physics at this interface are those usually implemented in highresolution ice shelf cavern circulation models, the "three-equations model" of Hellmer and Olbers (1989); Olbers and Hellmer (2010). Analyzing the solution as function of the overturning rate, a range of feasible values is extracted which meet the constraints claimed by the observations. The constraints are simply formulated as intervals of allowed values (the mean plus/minus an uncertainty), in our case for the temperature and salinity of the cavern outflow and the overall basal melt rate. The feasibility range for the overturning rate is then transferred by the model solution to feasibility ranges for prognostic model variables. This way we come up with a best estimate of the overturning and basal melt rate for the specific cavern. Depending on the a priori knowledge the data constraints - the feasibility range may by quite wide, narrow or even empty. In

Antarctic ice shelf caverns

D. Olbers et al.

Title Page

Abstract Introduction

Conclusions References

Tables Figures

14

$\Delta$

4

Back

$\triangleright$

Close

Full Screen / Esc

Printer-friendly Version

Interactive Discussion 
that case all solutions fail to pass through the constrained region in the data space and the data, coming from diverse sources such as hydrography and remote sensing, must be judged as incompatible.

In Sect. 2 the governing equations are derived and solved. In Sect. 3 the model setup 5 is described and the method of data constraints is explained simulating the Amery lce Shelf (AMY) cavern, followed by the application of the model to five more caverns, namely Pine Island Ice Shelf (PIIS), Ross (ROS), Fimbulisen (FIM), Ronne (RON), and Larsen C (LAR) ice shelves (Sect. 4). The paper ends with concluding remarks and an Appendix configuring the procedure for setting up the box model geometry.

\section{Governing equations and solution}

The model represents in a crude manner the circulation in oceanic caverns beneath ice shelves and aims at to provide an efficient calculation of melting and/or freezing rates from inflow conditions. The governing equations are formulated similar to the approach of Olbers and Hellmer (2010), but simplified with respect to the dynamics of

the overturning rate and pattern (which are now specified parameters) and extended to a multitude of boxes under the ice draft (see Fig. 1). In contrast to Olbers and Hellmer (2010), the attempt to model the water characteristics in front of the ice cavern is abandoned. The model is thus restricted to the immediate cavern domain and includes an arbitrarily large number of boxes beneath the ice draft and a single bottom box (labeled temperature and salinity are formulated as balance between (horizontal and vertical) advection, (vertical) diffusion and heat and freshwater exchange with the ice shelf by melting/freezing.

Antarctic ice shelf caverns

D. Olbers et al.

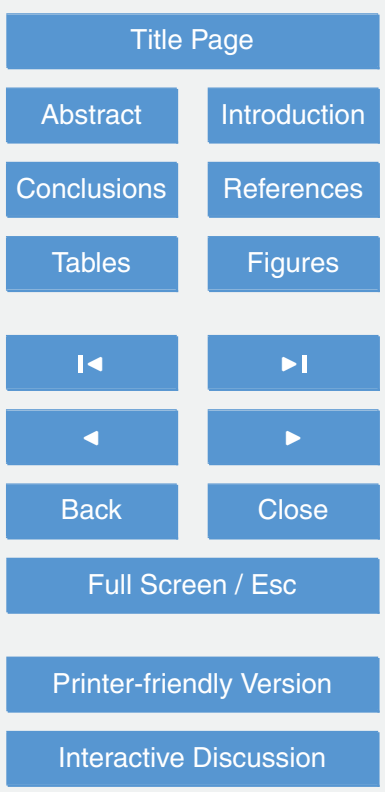


We regard a particular sub-ice box with volume $V$ and contact area $A$ to the ice. The heat and salt balances are written as:

$V \frac{\mathrm{d} T}{\mathrm{~d} t}=(u-w) T_{0}+w T_{\mathrm{d}}-u T-A k\left(T-T_{\mathrm{d}}\right)+A\left(\gamma_{\mathrm{T}}+m\right)\left(T_{\mathrm{f}}-T\right)$

8, 919-951, 2014

$V \frac{\mathrm{d} S}{\mathrm{~d} t}=(u-w) S_{0}+w S_{\mathrm{d}}-u S-A K\left(S-S_{\mathrm{d}}\right)+A\left(\gamma_{\mathrm{S}}+m\right)\left(S_{\mathrm{f}}-S\right)$

Here $m$ is the local melt rate (negative for freezing), and $\gamma_{\mathrm{T}, \mathrm{S}}$ are the turbulent exchange coefficients for the layer next to the ice shelf base. Furthermore, $u$ is the horizontal advective volume flux $\left[\mathrm{m}^{3} \mathrm{~s}^{-1}\right.$ ], positive out of the box and towards the ice shelf front, and $\kappa=K_{\mathrm{v}} / h$ derives from vertical diffusion with a diffusivity $K_{\mathrm{v}}$ and a vertical scale $h$. The temperature $T_{0}$ and salinity $S_{0}$ are prescribed as inflow values from the preceding box in the system while $T_{\mathrm{d}}$ and $S_{\mathrm{d}}$ are the values in the bottom box. The model considers upwelling into the sub-ice box by incorporating a flux $w\left[\mathrm{~m}^{3} \mathrm{~s}^{-1}\right]$, directed from the deep box into the respective sub-ice box. Conservation of mass has been considered, i.e., $u-w$ enters from the upstream sub-ice box, $w$ from the deep box, and $u$ leaves to the downstream sub-ice box. Note that Eqs. (1) are valid only for $u>0$ and $w>0$.

The effect of the mixing terms is only marginal: deviations from the zero-mixing approach only occur for low transport values $q \sim A K$, which are typically $10^{3} \mathrm{~m}^{3} \mathrm{~s}^{-1}$. In view of other model deficiencies and the uncertainty in the prescribed values at the ice front we thus abandon the diffusive term in the present study. Without diffusion $T_{\mathrm{d}}$ and $S_{d}$ are fixed and equal to the respective inflow values at the ice shelf front. The linearized freezing temperature:

$T_{\mathrm{f}}=a S_{\mathrm{f}}+b-c p$

determines the freezing point of seawater for the box with pressure $p$, representative for the ice draft, and the constants $a=-0.057^{\circ} \mathrm{Cpss}^{-1}, b=0.0832^{\circ} \mathrm{C}$, and ${ }_{25} C=7.64 \times 10^{-4}{ }^{\circ} \mathrm{C} \mathrm{dbar}^{-1}$. The placement of the pressure point to calculate the freezing temperature Eq. (2) is a critical issue if the resolution is low. It is obvious that the

Antarctic ice shelf caverns

D. Olbers et al.

Title Page

Abstract Introduction

Conclusions References

Tables

Figures

14

$\Delta$

4

Back

$\triangleright$

Close

Full Screen / Esc

Printer-friendly Version

Interactive Discussion 
deeper the location in the respective box the higher the resulting local melt rate. In all applications of this study we have chosen the deepest point of the ice draft in the respective box for providing the pressure $p$ (for the resolution with 50 boxes, used in this study, the location of $p$ is irrelevant). The salinity $S_{f}$ is calculated from the "three5 equations model" (Hellmer and Olbers, 1989; Olbers and Hellmer, 2010), resulting in a quadratic equation for $S_{f}$, the salinity of the melting/freezing layer at the ice shelf base:

$\left(T_{\mathrm{f}}-T\right) S_{\mathrm{f}}-\delta\left(S_{\mathrm{f}}-S\right)=0$

with $\delta=\lambda \gamma_{\mathrm{S}} / \gamma_{\mathrm{T}}, \lambda=L / c_{p}=84 \mathrm{~K}$ (here $L$ is the latent heat of fusion and $c_{p}$ the specific 10 heat of seawater). The pressure $p$ is set as being representative for each box (see below). The solution is given by:

$S_{\mathrm{f}}=F(T, S)=\frac{1}{2 a}(T-b+c p+d)+\sqrt{\frac{1}{4 a^{2}}(T-b+c p+d)^{2}-\frac{d}{a} S}$

with $d=\lambda \gamma_{\mathrm{S}} / \gamma_{\mathrm{T}}$. The local melt rate is determined as:

$m=\gamma_{\mathrm{T}}\left(T-T_{\mathrm{f}}\right) /(v \lambda)$

15 where $v=\rho_{\text {ice }} / \rho_{\text {water }}=0.89$. In the following applications the values for $\gamma_{\top}=3 \times$ $10^{-5} \mathrm{~ms}^{-1}$ and $\gamma_{\mathrm{S}}=1.2 \times 10^{-6} \mathrm{~ms}^{-1}$ are fixed.

The $m$ term in Eqs. (1) accounts for the change of volume when melting or freezing occurs (Jenkins et al., 2001). It appears a bit anachronistic if this term is retained while other mass fluxes related to the ice dynamics are absent, which are important for reason but also because generally $\gamma_{\top} \gg \gamma_{S} \gg m$ applies. With respect to the ensemble of caverns investigated here, this assumption is questionable only for PIIS where melt rates of the order of $40 \mathrm{myr}^{-1}$ (Jacobs et al., 2011) are expected and $m$ thus has a similar size as $\gamma_{\mathrm{s}}$.

Antarctic ice shelf caverns

D. Olbers et al.

Title Page

Abstract Introduction

Conclusions References

Tables

Figures

14

$\Delta$

4

Back

Close

Full Screen / Esc

Printer-friendly Version

Interactive Discussion 
We now search for an analytical solution for the steady state of the system Eqs. (1)(5) for any of the sub-ice boxes, neglecting the $m$ correction and considering the equations with $k=0$. With the abbreviations $u_{\mathrm{T}}=\gamma_{\mathrm{T}} A, u_{\mathrm{S}}=\gamma_{\mathrm{S}} A$, we obtain the two equations:

$5 \quad\left(u+u_{\mathrm{T}}\right) T=(u-w) T_{0}+w T_{\mathrm{d}}+u_{\mathrm{T}}(a F(T, S)+b-c p)$

$\left(u+u_{\mathrm{S}}\right) S=(u-w) S_{0}+w S_{\mathrm{d}}+u_{\mathrm{S}} F(T, S)$

for temperature $T$ and salinity $S$ in the box. Mathematically, we find a quadratic equation for either $T$ or $S$, which is readily solved. However, only one solution conforms with the 10 positive root in $S_{f}$, as given by Eq. (4).

Knowing the solution for the outflow as function of the inflow for a single sub-ice box we may iterate it for an ensemble of subsequent boxes. The inflow values of temperature and salinity are then the outflow values of the upstream box. Counting the sub-ice boxes by $j=1, \cdots, n$, starting at the grounding line, the outward flux $u_{j}$ of box $j$

15 is given by $u_{j}=\sum_{i=1}^{j} w_{i}$. The upwelling $w_{i}$ pattern, which will be prescribed and used as a tuning parameter, might change from box to box. The total overturning strength is $q=u_{n}=\sum_{i=1}^{n} w_{i}$. The complete model is thus a stack of modules with the above described thermodynamics, with the inflow values of temperature and salinity into the bottom box at the grounding line and outflow $T_{n}, S_{n}$ at the front. The latter are then 20 determined as function of the upwelling pattern $w_{i}$, the inflow characteristics, and the other fixed parameters.

An important issue of modeling ocean-ice shelf interaction is the resolution of the cavern geometry. A two-box configuration along the ice shelf base, as used in Olbers and Hellmer (2010), is certainly too coarse to resolve the melting close to the grounding 25 line. The resolution of the present model can be increased at no expense as only additional modules of the above described dynamics have to be placed in the stack. Figure 2 compares the results for different resolutions of the AMY cavern by means of
TCD

8, 919-951, 2014

Antarctic ice shelf caverns

D. Olbers et al.

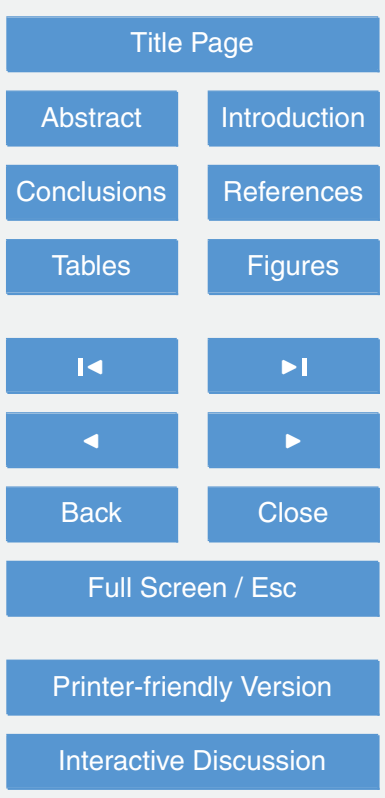


the mean basal melt rate:

$\bar{m}=\sum_{i=1}^{n} m_{i} A_{i} / \sum_{i=1}^{n} A_{i}$

TCD

8, 919-951, 2014

shown as function of the total overturning rate $q$ for a specific upwelling pattern (the "fast decrease" scenario, see Sect. 3). The conversion at about 50 sub-ice boxes be5 comes obvious. We emphasize that the distribution of melting and its rate in boxes close to the grounding line strongly depend on the number of boxes resolving the subice cavern. This difference is mainly due to the above mentioned pressure effect. In all applications of the present study we keep the number of sub-ice boxes fixed to 50 , corresponding to the blue line in Fig. 2.

\section{Model setup and evaluation - Amery Ice Shelf}

We first evaluate the impact of three scenarios of upwelling into the sub-ice boxes underneath AMY on melt rate and sub-ice temperature and salinity, representing different views on the interaction of the inflowing water with the ice shelf base. The upwelling $w$ is either distributed uniformly along the ice shelf's center line or concentrated near the 15 grounding line with either slow or fast decrease towards the cavern interior (Fig. 3 - left column). Such distribution directly controls the sub-ice overturning circulation reaching its maximum at the ice shelf front either linearly or exponentially (Fig. 3 - right column).

The averaged melt rate at the base of AMY as a function of the maximum overturning (red lines in Fig. 3 - right column) changes with the prescribed upwelling distribution. While the difference is small for the "uniform" and "slow-decrease" cases, mean melting is strongest when most of the upwelling occurs near the grounding line (Fig. 4). The latter demonstrates the importance of pressure, i.e. depth of the ice shelf base, on the in-situ freezing point and thus on the amount of potential heat for melting. The average melt rate is largest when most of the heat is delivered to - and used at - a deep ice shelf base.

Antarctic ice shelf caverns

D. Olbers et al.

Title Page
Abstract

Conclusions

Tables

14

4

Back

\section{Full Screen / Esc}

Printer-friendly Version

Interactive Discussion
Introduction

References

Figures

$\rightarrow$

$\triangleright$

Close

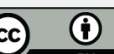


The corresponding $T / S$ diagrams (Fig. 5) show two significant differences for the properties of the sub-ice boxes, namely (1) a warmer temperature minimum for upwelling concentrated near the grounding line and small overturning rates together with (2) a smaller spread of the $T / S$ lines. The latter becomes smaller as the bulk of up5 welling moves towards the grounding zone. All lines start at the inflow values (upper right corner) following the "Gade line" (Gade, 1979), which represents the dilution relation for ice melting/forming in sea water, towards the salinity minimum and related in-situ freezing temperature. The latter increases as the water reaches the freezing point at lower pressure, i.e. shallower ice shelf base. Beyond this point freezing occurs, 10 adding salt and heat to the sub-ice boxes. Deviations from the straight line are due to the upwelling, which extends to the ice shelf front in the "uniform" case and prevents the formation of ice in the sub-ice boxes (Fig. 6 - upper left panel). With no upwelling along most of the ice shelf base and strong overturning the $T / S$ characteristics follow the "Gade-line" (Fig. 5 - right panel).

15 The impact of different upwelling distributions on the melt/freeze pattern and related temperature and salinity in the sub-AMY boxes as well as at the ocean/AMY interface is shown in Fig. 6. As mentioned above, uniform upwelling along the ice shelf base cuts off ice formation for low overturning rates, preventing the $T / S$ characteristics from following the "Gade line". In contrast, intense upwelling in the grounding zone slightly 20 reduces the fast decrease of melting but causes an earlier and a more pronounced shift into the freezing zone. Especially for low overturning rates part of the basal mass loss is compensated by the basal accretion of ice. Temperatures and salinities in the subice boxes almost follow the same pattern with a fast reduction over the grounding zone followed by a moderate increase towards the ice shelf front. The reduction becomes "fast decrease" upwelling scenario (Fig . 6 - lower row). Non-uniform upwelling causes a crossing of the $T / S$ lines near the ice shelf front, indicating either intense freshening of the sub-ice boxes due to longer lasting melting for high overturning or intense salt rejection due to longer lasting freezing for low overturning.
TCD

8, 919-951, 2014

Antarctic ice shelf caverns

D. Olbers et al.

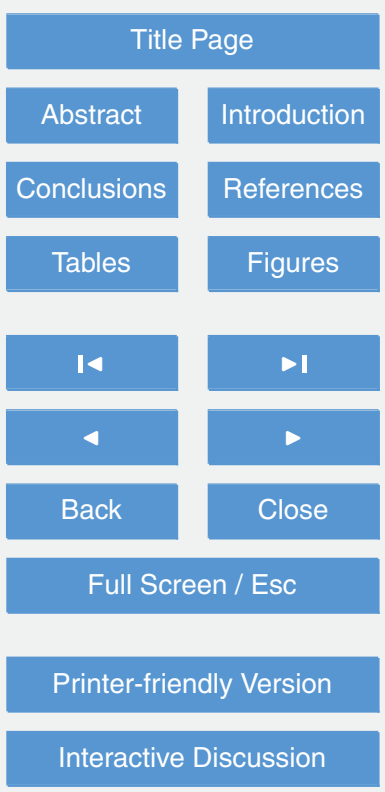


In summary, the pattern of upwelling into the sub-ice boxes has a significant impact on the basal mass flux and thus on the ice thickness distribution with consequences for the ice shelf dynamics, e.g. Determann (1991).

\section{Data-constrained application}

5 In the following, we use the 50-box version for five other caverns located around Antarctica: Pine Island Ice Shelf (PIIS), Ross (ROS), Fimbulisen (FIM), Ronne (RON), and Larsen C (LAR) ice shelves. As for AMY, the inflow temperature and salinity, $T_{d}$ and $S_{d}$, are chosen from hydrographic observations at the respective cavern front. To compare the model output with observations we concentrate on the measured hydrographic outflow characteristics, $T_{n}$ and $S_{n}$, and the mean basal melt rate $\bar{m}$. The most likely values of $T_{n}, S_{n}$ and $\bar{m}$, including reasonable uncertainties (as minima and maxima), are listed in Table 1, obtained from observations as referenced. Though the minima-maxima constraints are certainly a bit arbitrary (Table 2), the entirety of constraints should represent the feasibility space reasonably well.

15 The model is evaluated for a certain range of transport values $q$ in a specified upwelling scenario and fixed values for the other parameters (Table 1). From a mathematical point of view, we are looking at the trajectory $T_{n}(q), S_{n}(q)$, and $\bar{m}(q)$ in the three-dimensional space with coordinates $T_{n}, S_{n}$ and $\bar{m}$. A rough measure of consistency of the model and the data with their uncertainties is found when the trajectory

enters the constraing box defined by $T_{n} \pm \Delta T_{n}, S_{n} \pm \Delta S_{n}, \bar{m} \pm \Delta \bar{m}$ derived from the constraints of minimum and maximum values. The values $q_{\min }$ of entrance of the trajectory into and $q_{\max }$ of exit of the trajectory out of the constraining box defines the feasibility range $q_{\min }<q<q_{\max }$ where the model has solutions consistent with all constraints. If non-empty, the feasibility range is plotted as black line segment in the following figures.

We continue with AMY to illustrate the data constraint method, though AMY turns out to be an extreme case. Within the given thresholds only the "fast decrease" scenario (blue line) is able to meet all constraints (Fig. 7) for the interval $q_{\min }=0.08 \mathrm{~Sv}<$
Antarctic ice shelf caverns

D. Olbers et al.

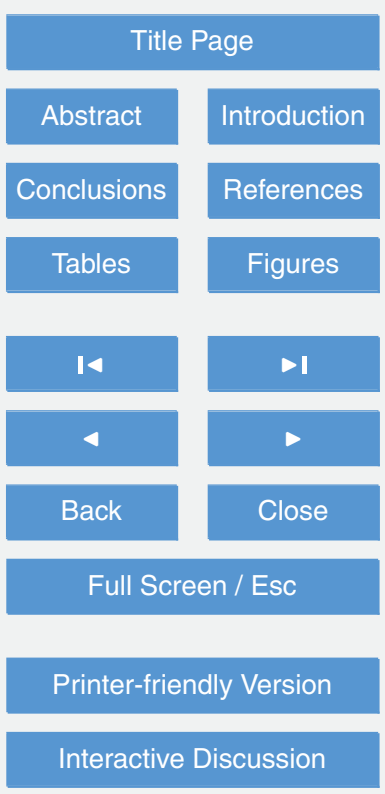


$q<q_{\max }=0.09 \mathrm{~Sv}\left(1 \mathrm{~Sv}=1 \times 10^{-6} \mathrm{~m}^{3} \mathrm{~s}^{-1}\right.$; Table 2$)$. Note that only a few hundredth of a degree warmer outflow temperature (right panel) would eliminate all consistent solutions. The constraint on salinity is not effective for the "fast decrease" case.

The effectiveness of the different constraints on the solution and feasibility domain 5 for the remaining suite of caverns is demonstrated in Figs. 8 to 12 . Certainly due to its width and probably two quasi independent sub-ice circulation regimes (Hellmer and Jacobs, 1995; Assmann et al., 2003), the hydrographic constraints for ROS are very wide leaving the remote sensed melt rate as the only sensible constraint (Fig. 8). On the other hand, our study shows that the melt rate is compatible with the hydrographic conditions along the ROS front for all upwelling scenarios and for the interval $q_{\text {min }}=$ $0.28 \mathrm{~Sv}<q<q_{\max }=1.24 \mathrm{~Sv}$ (Table 2). FIM, also an ice shelf with characteristics of inflow and outflow difficult to define, is bounded at both ends by the melt rate and, in addition, at the upper end by salinity (Fig. 9). If we assume the FIM melt rate to be the most trustable constraint, the temperature and salinity range of the outflow might be narrower than inferred from existing observations. In turn, the uncertainty of melting might be larger than the remotely sensed data is adding up to. The range of solutions for RON (Fig. 10), the other large ice shelf of our study, shows similarities with both ROS (temperature vs. salinity) and AMY (melt rate vs. temperature). Since connected to the Filchner Ice Shelf cavern at its southeastern corner (Nicholls et al., 2001), the 20 used outflow temperature (Table 1) might cover only part of the water masses modified at the base of RON. A slightly colder outflow would allow all upwelling scenarios to contribute to the solution (Table 2); the constraint on salinity is not effective for all cases. Nevertheless, based on our results and the constraints used, upwelling underneath RON seems to be more uniform along the base (melt rate vs. temperature) while more concentrated near the grounding line for AMY (temperature vs. salinity). An interesting feature of the dependence of $T_{n}, S_{n}$, and $\bar{m}$ on $q$ is that some caverns show a distinct minimum for a non-zero $q$ (not shown). This leads to two separated feasibility intervals as evident in the solution for LAR (Fig. 11). The latter is the only ice shelf which has a minimum overturning, and thus minimum melt rate, equal zero (Table 2).

Antarctic ice shelf caverns

D. Olbers et al.

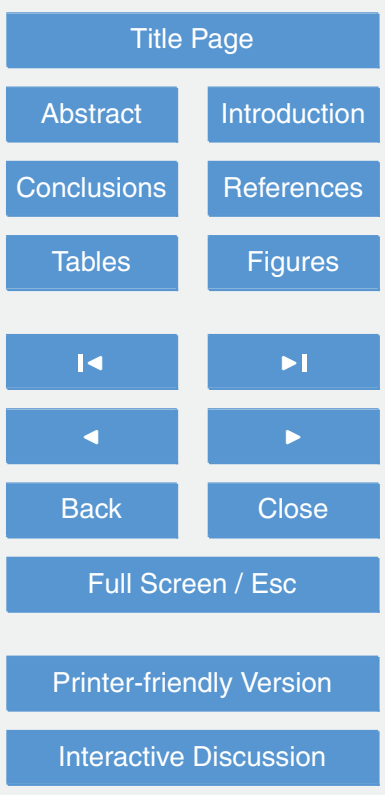

Interactive Discussion 
The results for PIIS are an excellent example for illustrating the scope of application of this study. While the hydrographic conditions in front of the ice shelf are quite well known, e.g. Jacobs et al. (2011), the mean basal melting changes significantly depending on the method/analysis applied (Jacobs et al., 1996; Hellmer et al., 1998;

5 Shepherd et al., 2004; Payne et al., 2007; Nakayama et al., 2013). The melt rate vs. salinity diagram (Fig. 12 - left) indicates that some fresher outflow (at the southern coast) might have been missed by the observations, but the melt rate vs. temperature diagram (Fig. 12 - right) convincingly shows that the mean melt rate (plus some uncertainty) used from Rignot et al. (2013) is not compatible with the observations, 10 independent of the upwelling secenario prescribed. Since we actually consider a 3dimensional space for the solution, the missing pass through the melt rate/temperature plane is sufficient to result in no solutions for PIIS (Table 2). In turn, a slightly higher melting, still within the published range, would allow for all scenarios to contribute to the solution. It is interesting to note, that similar to AMY and RON the "uniform" case provides solutions which are closest to the range constrained by the observations.

We are aware that other uncertain model parameters exist than those taken into account so far. Of most interest are the inflow characteristics $T_{\mathrm{d}}$ and $S_{\mathrm{d}}$, which are not well constrained and may vary considerably. If more data for more variables becomes available, on melting near the grounding line and/or the ice front, the box constraints 20 must be applied in a space of higher dimension than three. However, this route is beyond the scope of the present study.

\section{Conclusions}

We developed a simple numerical tool which allows for estimating the overturning rate (strength of advection within the cavern), the pattern of local basal melting, and the temperature and salinity in Antarctic ice shelf caverns. The tool combines an analytical solution of the advective/diffusive balances of heat and salt with hydrographic data of the outflow and the total melt rate. The solution is constrained by finding feasible
TCD

8, 919-951, 2014

Antarctic ice shelf caverns

D. Olbers et al.

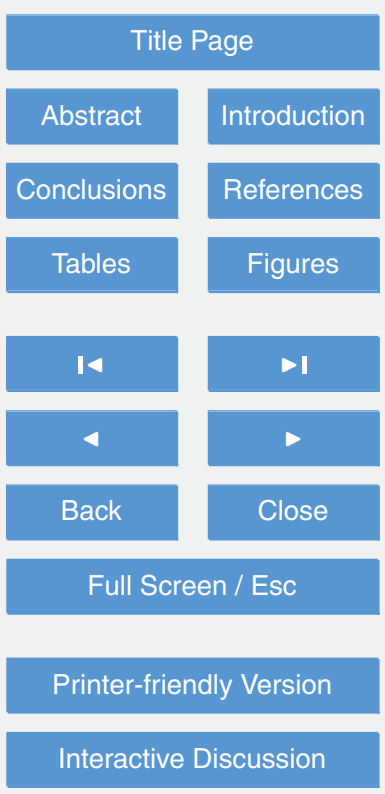


ranges for the strength of advection. The method is similar to the conventional linear programming, except that the model used here is non-linear because of the non-linear melting/freezing physics at the ice shelf base. The spatial resolution along the assumed path of water through the cavern can be arbitrarily high, however, across the cavern

5 a simple box-type pattern is used, adjusted to the local width. Given the temperature and salinity of the deep flow into the cavern and reasonable limits for the outflow temperature and salinity and on the total melting/freezing rate, a range of feasible values for the overturning rate is determined. The along-cavern dependence of temperature, salinity, and basal melt/freeze rate follows from the analytical solution.

10 The box model has been applied to six Antarctic sub-ice caverns. The constraining data comes from diverse observations and high-resolution numerical models. The results reveal that some caverns have reasonably constrained solutions while others are only insufficiently constrained or have almost conflicting constraints. For the first ensemble of our suite of caverns, namely Amery (AMY), Ross (ROS), and Pine Island 15 characteristics of inflow, outflow, and total basal melt rate. The observational data for
the second ensemble, namely Fimbulisen (FIM) and Larsen (LAR), yields a quite broad range of feasible solutions, i.e., further observations are necessary to reduce the range of the prescribed characteristics. Ronne (RON), on the other hand, is at the brink of having no feasible solution. This might be due to the complex interaction of the RON cavern with the neighboring Filchner cavern around the southern tip of Berkner Island (Nicholls et al., 2001) which does not allow for a clear characterization of the inflow and, in particular, outflow conditions. The limitations of the model might be responsible for some of the insufficiencies, first to mention the coarse resolution across the cavern and the absence of any horizontal circulation. However, our method, applied to six Antarctic ice shelves, seems suitable for testing the compatability of remotely sensed mass loss at the base of an ice shelf with the observed hydrography in front of it.
TCD

8, 919-951, 2014

Antarctic ice shelf caverns

D. Olbers et al.

Title Page

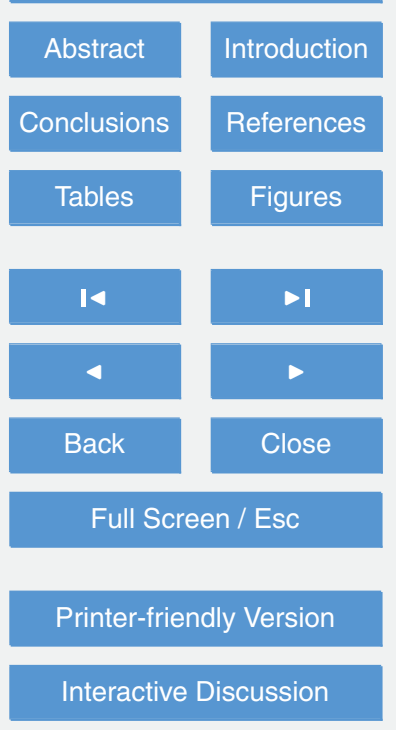




\section{Appendix A}

\section{Generating the box geometry}

We briefly describe how the geometry of the caverns is simplified to yield the structure of the box model. We use realistic data of the ice shelf draft and bathymetry to provide 5 reliable areal estimates of the interface between ocean and ice. The geometry of all caverns is taken from a consistent data set (Timmermann et al., 2010) and extracted with a script provided by R. Timmermann. Figure 13 shows the conditions for the AMY cavern. To define a characteristic two-dimensional data set, a starting point and an end point is defined. Only data taken from a small area around the connecting line (CL) between the two points is used. To obtain data without artifacts near the grounding line, all points with difference between the draft and the bathymetry below a certain tolerance threshold are discarded. For instance, the limiting points of CL taken for AMY are $73.267^{\circ} \mathrm{E}, 67.017^{\circ} \mathrm{S}$ and $68.633^{\circ} \mathrm{E}, 72.55^{\circ} \mathrm{S}$, the width of the area was $0.02^{\circ}$ in latitude for each point of longitude along $\mathrm{CL}$, and the tolerance threshold was $280 \mathrm{~m}$. 15 If there are obstacles found along a particular CL, the line is divided into multiples between additional coordinate points, which are defined to circumvent those obstacles. The length of the ice shelf is determined by computing the distance between the first coordinate of the available data and following coordinates until the last coordinate at the ice shelf front.

The bathymetry and draft data, obtained this way, are represented by a multi-degree polynomial fit. The pressure along CL of each cavern is computed from these polynomial functions (lower panel of Fig. 13). The length of each box is chosen in an equidistant way according to the specified total number of boxes beneath the ice shelf. The width of each box is calculated from a cross section perpendicular to the connecting 25 line.

Each box has two limiting pressure points $p_{\text {left }}$ and $p_{\text {right }}$ along $\mathrm{CL}$, and the pressure $p$, entering the freezing point equation Eq. (2) for the respective box, is calculated
8, 919-951, 2014

Antarctic ice shelf caverns

D. Olbers et al.

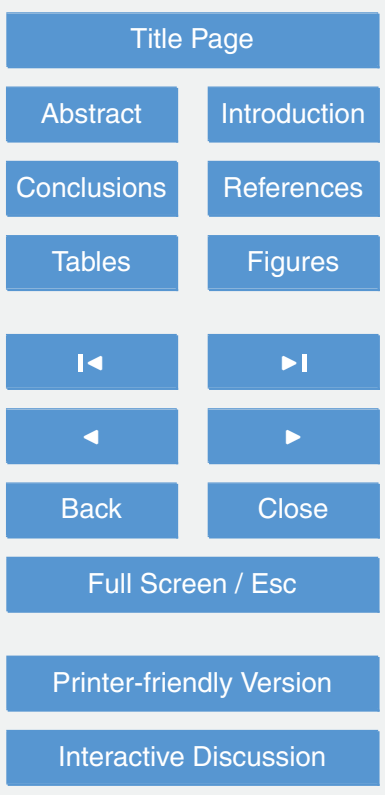


from $p=p_{\text {left }}$. The heights of the respective upper boxes are set by $\left(h_{\text {bathy }}-h_{\text {draft }}\right) / 3$. Other choices are straightforward. The box configuration shown in Fig. 1 represents the conditions for AMY with a total of 50 sub-ice boxes.

Acknowledgements. The authors would like to thank R. Timmermann for providing the data 5 of sub-ice bathymetry and draft and A. Jenkins for very constructive comments on an earlier version of this paper.

\section{References}

Assmann, K., Hellmer, H. H., and Beckmann, A.: Seasonal variation in circulation and water mass distribution on the Ross Sea continental shelf, Antarct. Sci., 15, 3-11, 2003. 929

Beckmann, A., Hellmer, H., and Timmermann, R.: A numerical model of the Weddell Sea: large scale circulation and water mass distribution, J. Geophys. Res., 104, 23375-23391, 1999. 921

Corr, H., Doake, C., Jenkins, A., and Vaughan, D.: Investigations of an "ice plain" in the mouth of Pine Island Glacier, Antarctica, J. Glaciol., 47, 51-57, 2001. 920

15 Determann, J.: Numerical modelling of ice shelf dynamics, Antarct. Sci., 3, 187-194, 1991. 928

Gade, H. G.: Melting of ice in sea water: a primitive model with application to the Antarctic ice shelf and icebergs, J. Phys. Oceanogr., 9, 189-198, 1979. 927

Gerdes, R., Determann, J., and Grosfeld, K.: Ocean circulation beneath Filchner-Ronne Ice Shelf from three-dimensional model results, J. Geophys. Res., 104, 15827-15842, 1999. 921

Hellmer, H. H. and Jacobs, S. S.: Seasonal circulation under the eastern Ross Ice Shelf, Antarctica, J. Geophys. Res., 100, 10873-10885, 1995. 929

Hellmer, H. H. and Olbers, D. J.: A two-dimensional model for the thermohaline circulation under an ice shelf, Antarct. Sci., 1, 325-336, 1989. 920, 921, 924

25 Hellmer, H., Jacobs, S., and Jenkins, A.: Oceanic erosion of a floating Antarctic glacier in the Amundsen Sea, in: Ocean, Ice, and Atmosphere: Interactions at the Antarctic Continental Margin, edited by: Jacobs, S. and Weiss, R., Antarctic Research Series, vol. 75, American Geophysical Union, Washington DC, USA, 319-339, 1998. 930, 936
TCD

8, 919-951, 2014

Antarctic ice shelf caverns

D. Olbers et al.

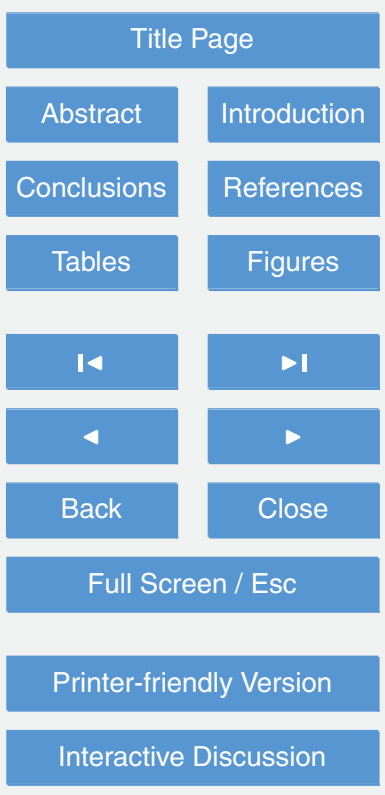


Holland, D. M. and Jenkins, A.: Modeling thermodynamic ice-ocean interactions at the base of an ice shelf, J. Phys. Oceanogr., 29, 1787-1800, 1999. 920

Jacobs, S. S. and Giulivi, C. F.: Interannual ocean and sea ice variability in the Ross Sea, in: Ocean, Ice and Atmosphere: Interactions at Antarctic Continental Margin, edited by: Ja-

5 cobs, S. S. and Weiss, R., Antarctic Research Series, vol. 75, American Geophysical Union, Washington DC, USA, 1998. 936

Jacobs, S. S., Hellmer, H. H., and Jenkins, A.: Antarctic ice sheet melting in the Southeast Pacific, Geophys. Res. Lett., 23, 957-960, 1996. 930

Jacobs, S. S., Jenkins, A., Giulivi, C. F., and Dutrieux, P.: Stronger ocean circulation and increased melting under Pine Island Glacier ice shelf, Nat. Geosci., 4, 519-523, 2011. 924, 930

Jenkins, A.: A one-dimensional model of ice shelf-ocean interaction, J. Geophys. Res., 96, 20671-20677, 1991. 920

Jenkins, A., Hellmer, H. H., and Holland, D. M.: The role of meltwater advection in the formula15 tion of conservative boundary conditions at an ice-ocean interface, J. Phys. Oceanogr., 31, 285-296, 2001. 924

Jenkins, A., Dutrieux, P., Jacobs, S., McPhail, S., Perrett, J., Webb, A., and White, D.: Observations beneath Pine Island Glacier in West Antarctica and implications for its retreat, Nat. Geosci., 3, 468-472, 2010. 920

Losch, M.: Modeling ice shelf cavities in a z-coordinate ocean general circulation model, J. Geophys. Res., 113, C08043, doi:10.1029/2007JC004368, 2008. 921

Nakayama, Y., Schröder, M., and Hellmer, H. H.: From circumpolar deep water to the glacial meltwater plume on the eastern Amundsen Shelf, Deep-Sea Res., 77, 50-62, 2013. 930

Nicholls, K. W., Østerhus, S., Makinson, K., and Johnson, M. R.: Oceanographic conditions south of Berkner Island, beneath Filchner-Ronne Ice Shelf, Antarctica, J. Geophys. Res., 106, 11481-11492, 2001. 929, 931

Nicholls, K. W., Padman, L., Schröder, M., Woodgate, R. A., Jenkins, A., and Østerhus, S.: Water mass modification over the continental shelf north of Ronne Ice Shelf, Antarctica, J. Geophys. Res., 108, 3260, doi:10.1029/2002JC001713, 2003. 936

30 Nicholls, K. W., Pudsey, C. J., and Morris, P.: Summertime water masses off the northern Larsen C Ice Shelf, Antarctica, Geophys. Res. Lett., 31, L09309, doi:10.1029/2004GL019924, 2004. 936

Antarctic ice shelf caverns

D. Olbers et al.

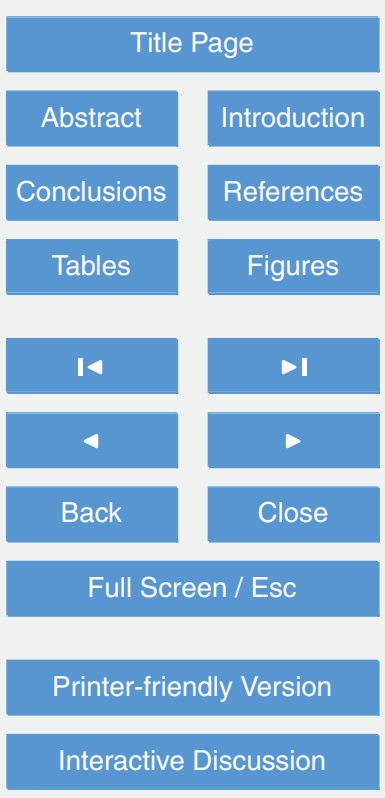


Nicholls, K. W., Abrahamsen, E. P., Buck, J. J. H., Dodd, P. A., Goldblatt, C., Griffiths, G., Heywood, K. J., Hughes, N. E., Kaletzky, A., Lane-Serff, G. F., McPhail, S. D., Millard, N. W., Oliver, K. I. C., Perrett, J., Price, M. R., Pudsey, C. J., Saw, K., Stansfield, K., Stott, M. J., Wadhams, P., Webb, A. T., and Wilkinson, J. P.: Measurements beneath an Antarctic ice shelf using an autonomous underwater vehicle, Geophys. Res. Lett., 33, L08612, doi:10.1029/2006GL025998, 2006. 920, 936

Olbers, D. and Hellmer, H. H.: A box model of circulation and melting in ice shelf caverns, Ocean Dynam., 60, 141-153, 2010. 920, 921, 922, 924, 925

Payne, A. J., Holland, P. R., Shepherd, A. P., Rutt, I. C., Jenkins, A., and Joughin, I.: Numerical modeling of ocean-ice interactions under Pine Island Bay's Ice Shelf, J. Geophys. Res., 112, C10019, doi:10.1029/2006JC003733, 2007. 930

Rignot, E.: Fast recession of a West Antarctic glacier, Science, 281, 549-551, 1998. 920

Rignot, E., Jacobs, S. S., Mouginot, J., and Scheuchl, B.: Ice shelf melting around Antarctica, Science, 341, 266-270, 2013. 920, 930, 936

Shepherd, A., Wingham, D., and Rignot, E.: Warm ocean is eroding West Antarctic ice sheet, Geophys. Res. Lett., 31, L23404, doi:10.1029/2004GL021106, 2004. 920, 930

Timmermann, R., Le Brocq, A., Deen, T., Domack, E., Dutrieux, P., Galton-Fenzi, B., Hellmer, H., Humbert, A., Jansen, D., Jenkins, A., Lambrecht, A., Makinson, K., Niederjasper, F., Nitsche, F., Nøst, O. A., Smedsrud, L. H., and Smith, W. H. F.: A consistent data set of Antarctic ice sheet topography, cavity geometry, and global bathymetry, Earth Syst. Sci. Data, 2, 261-273, doi:10.5194/essd-2-261-2010, 2010. 932, 938, 951

Timmermann, R., Wang, Q., and Hellmer, H. H.: Quantification of ice shelf basal melting using a global finite-element sea ice-ice shelf-ocean model, Ann. Glaciol., 53, 303-314, 2012. 921

Wong, A. P. S., Bindoff, N., and Forbes, A.: Ocean-ice shelf interaction and possible bottom water formation in Prydz Bay, Antarctica, in: Ocean, Ice and Atmosphere: Interactions at Antarctic Continental Margin, edited by: Jacobs, S. S., and Weiss, R., Antarctic Research Series, vol. 75, American Geophysical Union, Washington DC, USA, 173-187, 1998. 936
TCD

8, 919-951, 2014

Antarctic ice shelf caverns

D. Olbers et al.

Title Page

Abstract Introduction

Conclusions References

Tables Figures

14 $\rightarrow$

4

Back

$\triangleright$

Close

Full Screen / Esc

Printer-friendly Version

Interactive Discussion 
Table 1. Temperature $T_{\mathrm{d}}\left[{ }^{\circ} \mathrm{C}\right]$ and salinity $S_{\mathrm{d}}$ of the cavern inflows and the constraints (appropriate minima and maxima) on the mean basal melt rate $\left[\mathrm{ma}^{-1}\right]$ and temperature $\left[{ }^{\circ} \mathrm{C}\right]$ and salinity in the front box, according to observations from sections along the ice shelf front and other data taken from the literature. Melt rate data from Rignot et al. (2013). Hydrography: AMY (Wong et al., 1998), PIIS (Hellmer et al., 1998), ROS (Jacobs and Giulivi, 1998), FIM (Nicholls et al., 2006), RON (Nicholls et al., 2003), LAR (Nicholls et al., 2004).

\begin{tabular}{lrrrrrrrr}
\hline Cavern & $T_{\mathrm{d}}$ & $S_{\mathrm{d}}$ & $\bar{m}_{\min }$ & $\bar{m}_{\max }$ & $\min T_{n}$ & $\max T_{n}$ & $\min S_{n}$ & $\max S_{n}$ \\
\hline AMY & -1.85 & 34.53 & 0.2 & 1.0 & -2.1 & -2 & 34.45 & 34.5 \\
ROS & -1.7 & 34.65 & 0.1 & 0.5 & -2.1 & -1.95 & 34.4 & 34.65 \\
FIM & -1.87 & 34.35 & 0.4 & 0.8 & -2.1 & -1.9 & 34.23 & 34.32 \\
RON & -1.95 & 34.7 & 0.2 & 0.4 & -2.1 & -2 & 34.6 & 34.75 \\
LAR & -1.7 & 34.61 & 0.0 & 1.4 & -2.04 & -1.9 & 34.45 & 34.59 \\
PIIS & 1.05 & 34.67 & 15.2 & 17.2 & -0.4 & 0 & 34.1 & 34.4
\end{tabular}

Antarctic ice shelf caverns

D. Olbers et al.

Title Page

Abstract

Conclusions

Tables

14

4

Back
Introduction

References

Figures

$>$ I

$>$

Close

Full Screen / Esc

Printer-friendly Version

Interactive Discussion 
Table 2. Limits of the feasibility region for the six caverns of Amery (AMY), Ross (ROS), Fimbulisen (FIM), Ronne (RON), Larsen C (LAR), and Pine Island (PIIS) ice shelves for three upwelling scenarios: overturning circulation $q[\mathrm{~Sv}]$, mean basal melt rate $\bar{m}\left[\mathrm{ma}^{-1}\right.$ ], outflow temperature $T\left[{ }^{\circ} \mathrm{C}\right]$, and outflow salinity $S$.

\begin{tabular}{|c|c|c|c|c|c|c|c|c|}
\hline Cavern & $q_{\min }$ & $q_{\max }$ & $\bar{m}_{\min }$ & $\bar{m}_{\max }$ & $T_{\min }$ & $T_{\max }$ & $S_{\min }$ & $S_{\max }$ \\
\hline \multicolumn{9}{|c|}{ uniform } \\
\hline AMY & - & - & - & - & - & - & - & - \\
\hline ROS & 0.28 & 1.38 & 0.1 & 0.5 & -2.04 & -2.03 & 34.51 & 34.51 \\
\hline FIM & 0.14 & 0.32 & 0.41 & 0.8 & -2.05 & -2.02 & 34.27 & 34.29 \\
\hline RON & 0.7 & 0.97 & 0.2 & 0.29 & -2.1 & -2.09 & 34.64 & 34.64 \\
\hline LAR & 0 & 0.81 & 0 & 1.4 & -2.02 & -1.92 & 34.47 & 34.52 \\
\hline PIIS & - & - & - & - & - & - & - & - \\
\hline \multicolumn{9}{|c|}{ slow decrease } \\
\hline AMY & - & - & - & - & - & - & - & - \\
\hline ROS & 0.32 & 1.5 & 0.1 & 0.5 & -2.06 & -2.04 & 34.5 & 34.51 \\
\hline FIM & 0.14 & 0.31 & 0.41 & 0.8 & -2.07 & -2.05 & 34.27 & 34.28 \\
\hline RON & - & - & - & - & - & - & - & - \\
\hline LAR & 0 & 0.76 & 0 & 1.4 & -2.03 & -1.97 & 34.47 & 34.5 \\
\hline PIIS & - & - & - & - & - & - & - & - \\
\hline \multicolumn{9}{|c|}{ fast decrease } \\
\hline AMY & 0.08 & 0.09 & 0.19 & 0.21 & -2.1 & -2.1 & 34.46 & 34.46 \\
\hline ROS & 0.27 & 1.24 & 0.1 & 0.5 & -2.07 & -2.04 & 34.5 & 34.51 \\
\hline FIM & 0.11 & 0.24 & 0.41 & 0.79 & -2.09 & -2.07 & 34.26 & 34.27 \\
\hline RON & - & - & - & - & - & - & - & - \\
\hline LAR & 0 & 0.56 & 0 & 1.4 & -2.04 & -2 & 34.47 & 34.48 \\
\hline PIIS & - & - & - & - & - & - & - & - \\
\hline
\end{tabular}

TCD

8, 919-951, 2014

Antarctic ice shelf caverns

D. Olbers et al.

Title Page

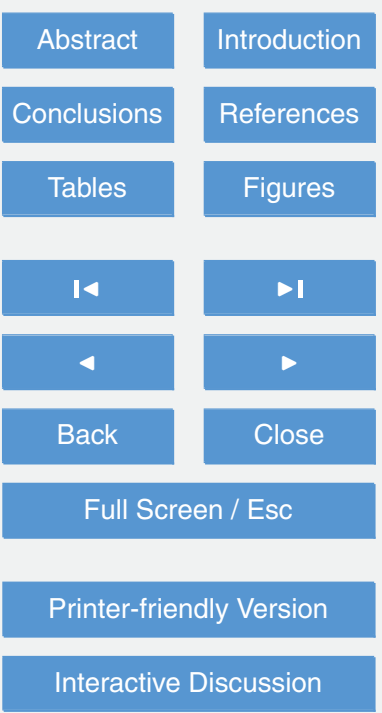




\section{TCD}

\section{8, 919-951, 2014}

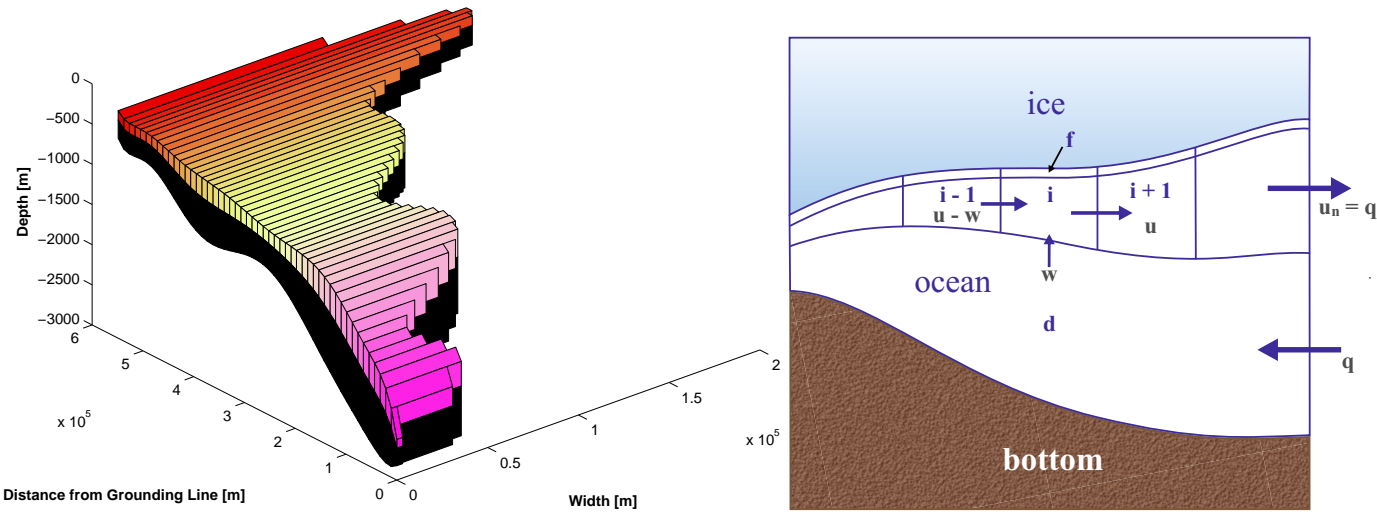

\section{Antarctic ice shelf}

caverns

D. Olbers et al.

\section{Title Page}

Fig. 1. (a) Model geometry of the Amery Ice Shelf (AMY) cavern with 50 boxes following the ice draft. The height of the upper boxes is set by $\left(h_{\text {bathy }}-h_{\text {draft }}\right) / 3$. One deep box (black) connects the ice shelf front (red) with the grounding line zone (purple). The cavern is viewed from the side with the boxes arranged to yield a plane side. Data for bottom topography and ice shelf draft is obtained from RTOPO-1 (Timmermann et al., 2010). (b) Sketch of the side view of the cavern showing ice, ocean, and bottom areas, bounded to the left by the grounding line and to the right by the ice-shelf front. Beneath the ice the freezing layer $f$ acts as transition between the ice and the sub-ice boxes, with the boxes $i-1, i$, and $i+1$ shown with inflow transports $(u-w, w)$ and outflow transport $u$ for box $i$. Below the sub-ice boxes there is the deep ocean box $d$. The inflow transport into box $d$ at the front has the magnitude $q$, and the same amount leaves the last sub-ice box at the ice-shelf front.

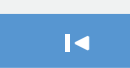

4

4

Back
$>$ I

$>$

Close

Full Screen / Esc

Printer-friendly Version

Interactive Discussion 


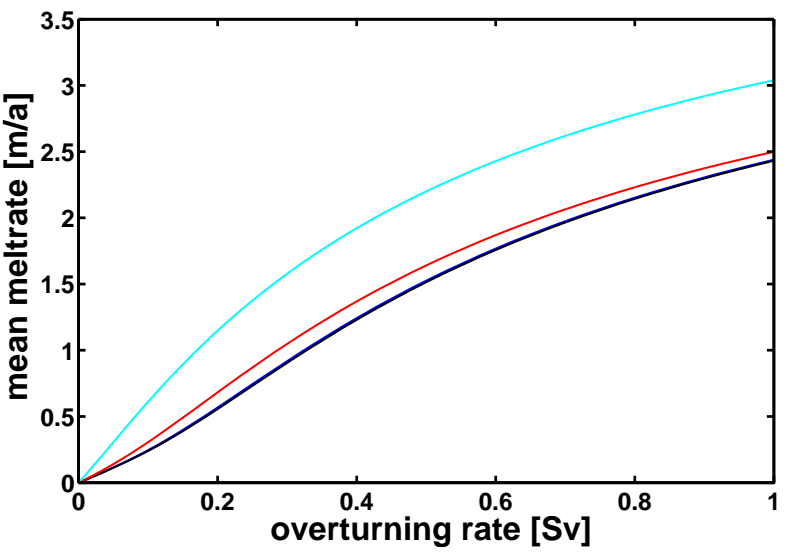

Introduction

Fig. 2. Mean melt rate for the AMY geometry with 3 (cyan), 10 (red), 50 (blue), and 100 (black) sub-ice boxes as function of the overturning $q\left(1 \mathrm{~Sv}=1 \times 10^{-6} \mathrm{~m}^{3} \mathrm{~s}^{-1}\right)$; the difference between 50 and 100 sub-ice boxes is minimal causing an overlap of the curves. Upwelling $w$ is predominantly close to the grounding line (the "fast decrease" scenario; further details are given in Sect. 3).

Antarctic ice shelf caverns

D. Olbers et al.

Title Page

Abstract

Conclusions

References

Tables

Figures

14

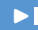

8, 919-951, 2014

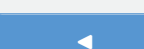

Back

Full Screen / Esc

Printer-friendly Version

Interactive Discussion 

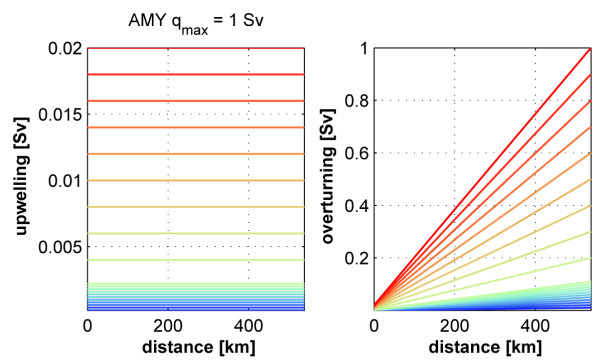

TCD

\section{8, 919-951, 2014}

Antarctic ice shelf caverns

D. Olbers et al.
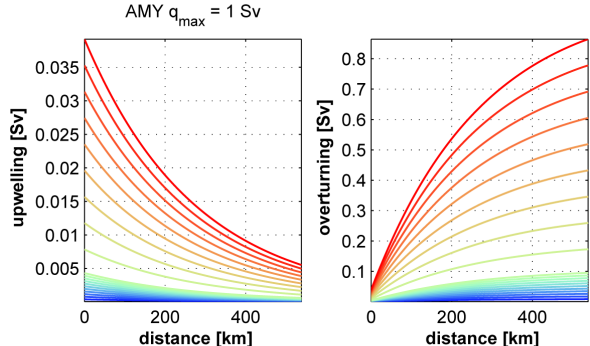

Title Page
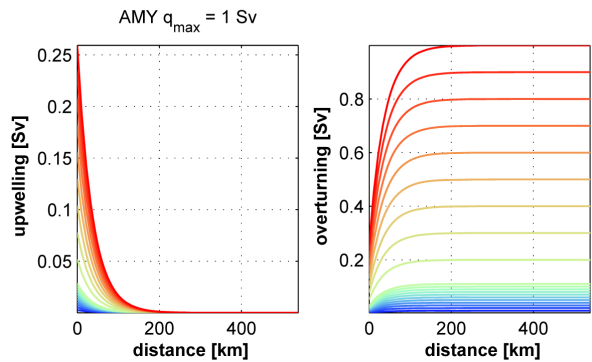

Fig. 3. For three upwelling scenarios: uniform upwelling (upper), slow decrease from grounding line (middle), fast decrease from grounding line (lower). The upwelling transport $w$ (left) and the horizontal transport $u$ (right) is shown as function of distance from the grounding line. 20 values of $q$ are considered: the blue curves are for the range $0<q<0.1 \mathrm{~Sv}\left(1 \mathrm{~Sv}=1 \times 10^{-6} \mathrm{~m}^{3} \mathrm{~s}^{-1}\right)$ in steps of $0.01 \mathrm{~Sv}$, proceeding then in steps of $0.1 \mathrm{~Sv}$ to $1.0 \mathrm{~Sv}$ (green to red).

Abstract

Introduction

Conclusions

References

Tables

Figures

14

$\rightarrow 1$

4

Back

Close

Full Screen / Esc

Printer-friendly Version

Interactive Discussion 


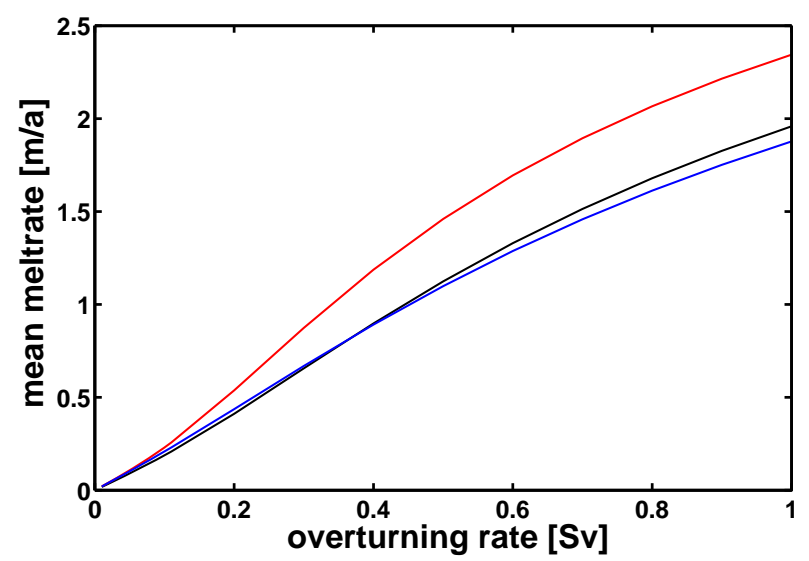

Fig. 4. Mean melt rate as function of the maximum overturning $q$ (red curves in Fig. 3): uniform upwelling case (blue), slow decrease from grounding line (black), fast decrease from grounding line (red).

\section{TCD}

8, 919-951, 2014

Antarctic ice shelf caverns

D. Olbers et al.

\section{Title Page}

Abstract

Introduction

Conclusions

References

Tables

Figures

14

$>1$

4

Back

Close

Full Screen / Esc

Printer-friendly Version

Interactive Discussion 

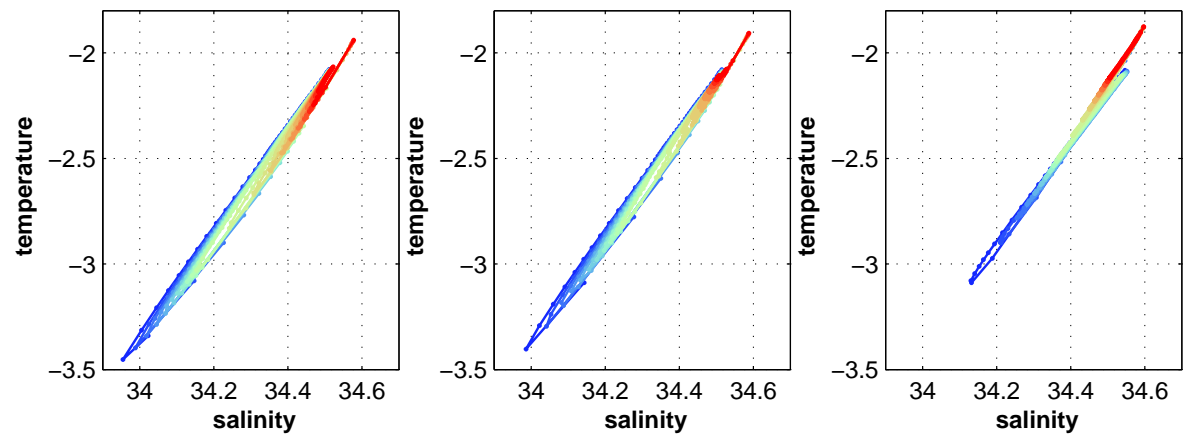

Fig. 5. $T / S$-diagram for all (50) sub-ice boxes and the suite of overturning rates (color coded as in Fig. 6): uniform upwelling scenario (left), slow decrease from grounding line (middle), fast decrease from grounding line (right).

TCD

8, 919-951, 2014

Antarctic ice shelf caverns

D. Olbers et al.

Title Page

Abstract

Introduction

Conclusions

References

Tables

Figures

14

$>$ I

4

Back

Close

Full Screen / Esc

Printer-friendly Version

Interactive Discussion 

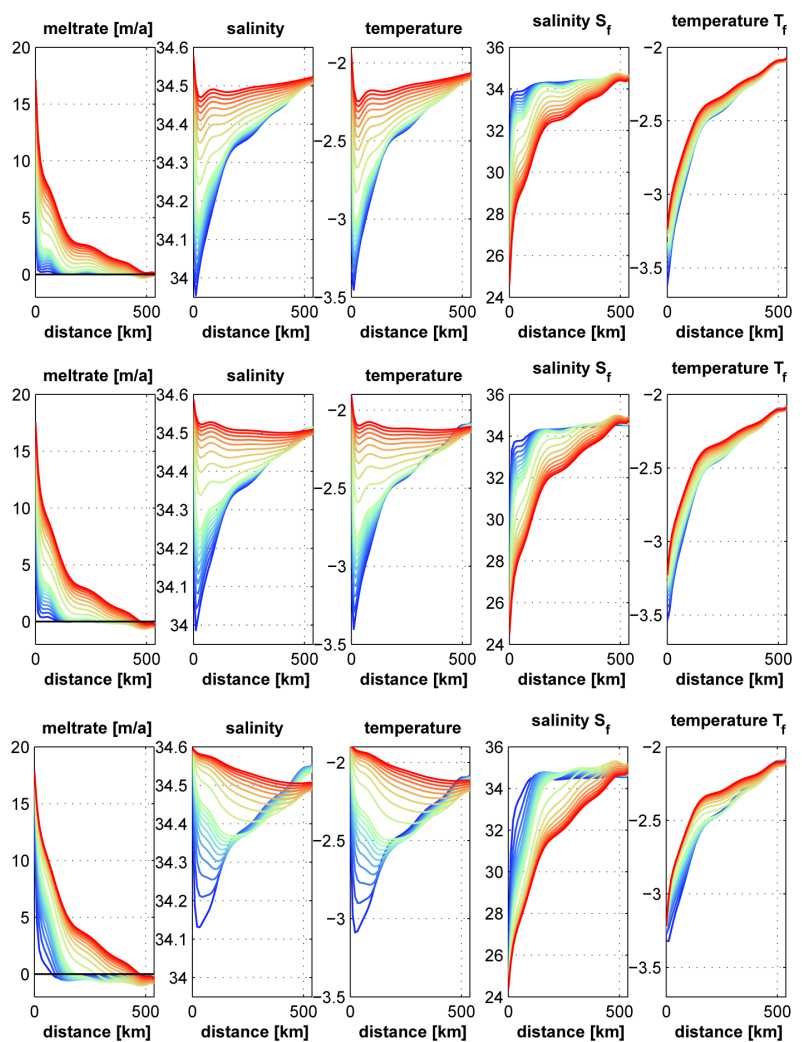

Fig. 6. Melt rates, salinity, and temperature in the boxes beneath AMY as function of distance from the grounding line for different $q$ values. The two right panels display the thermohaline state of the freezing layer (subscript $\mathrm{f}$ ). The blue curves are for the range $0<q<0.1 \mathrm{~Sv}$ ( $1 \mathrm{~Sv}=$ $1 \times 10^{-6} \mathrm{~m}^{3} \mathrm{~s}^{-1}$ ) in steps of $0.01 \mathrm{~Sv}$, proceeding then in steps of $0.1 \mathrm{~Sv}$ to $1.0 \mathrm{~Sv}$ (green to red). Uniform upwelling (upper row), slow decrease from grounding line (middle row), fast decrease from grounding line (lower row).

Antarctic ice shelf caverns

D. Olbers et al.

Title Page

Abstract

Conclusions

Tables

14

4

Back

Full Screen / Esc

Printer-friendly Version

Interactive Discussion 

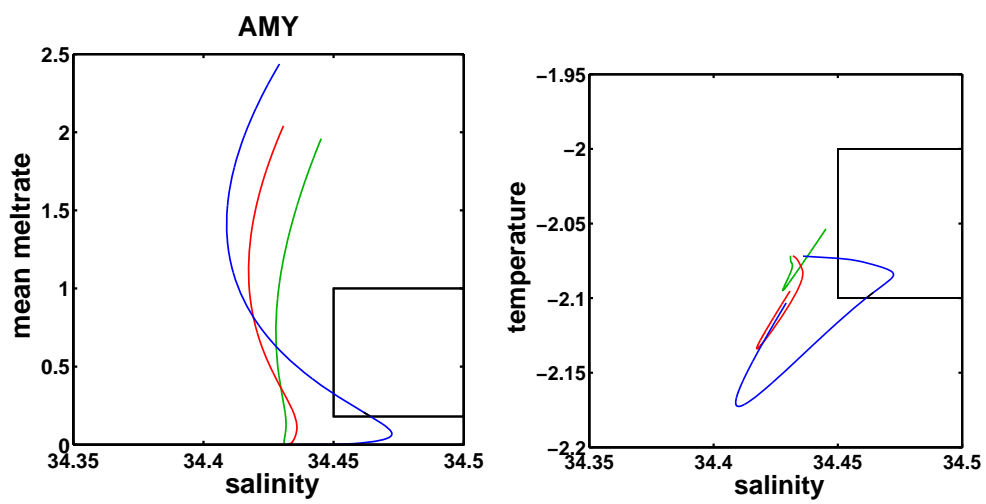

TCD

8, 919-951, 2014

Antarctic ice shelf caverns

D. Olbers et al.

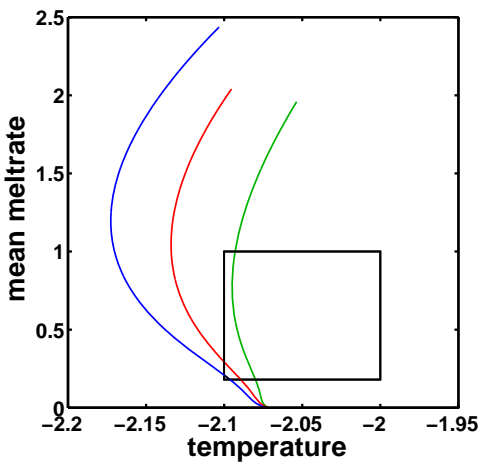

Title Page

Abstract

Conclusions

Tables

14

4

Back
Introduction

References

Figures

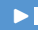

$>$

Close

Fig. 7. Salinity and temperature in the front box of Amery Ice Shelf (AMY), and the mean melt rate $\left[\mathrm{ma}^{-1}\right]$ as trajectories $T_{c}(q), S_{c}(q)$, and $\bar{m}(q)$ in the phase space. The three upwelling scenarios are plotted as green ("uniform"), red ("slow decrease") and blue ("fast decrease") curves, representing the two-dimensional views of the respective trajectories. The black portion of the curves, almost invisible for AMY due to a short pass through the melt rate/temperature plane (lower panel), indicates $q$ values, which are compatible with all constraints given by the black boxes.

Full Screen / Esc

Printer-friendly Version

Interactive Discussion 

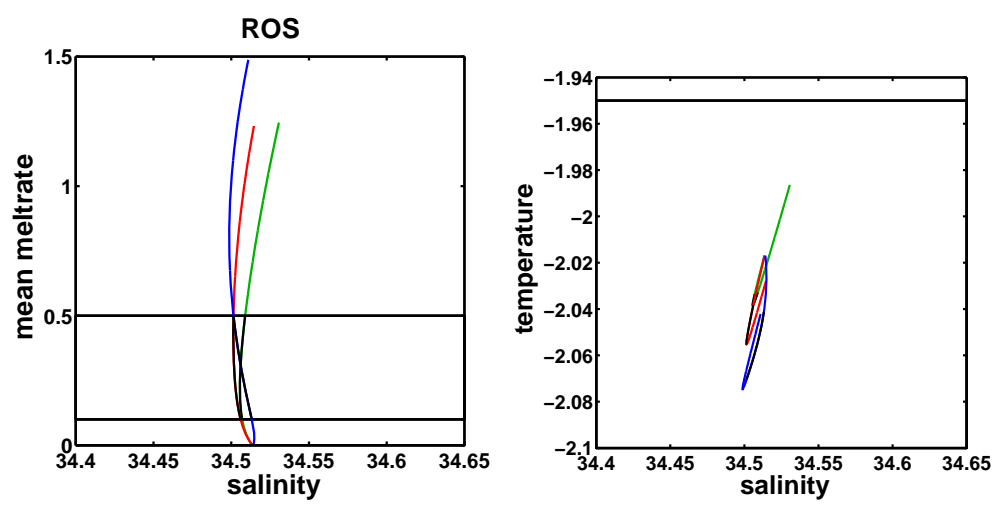

TCD

8, 919-951, 2014

Antarctic ice shelf caverns

D. Olbers et al.

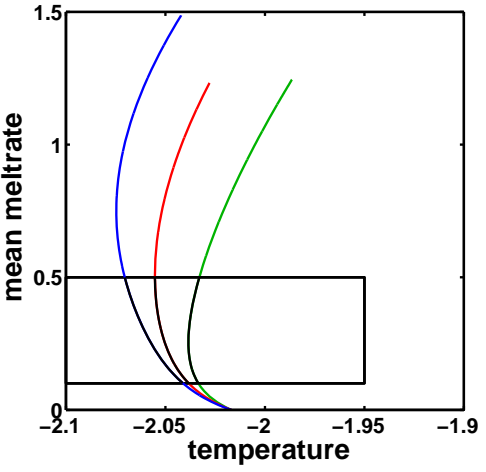

Title Page

Abstract

Introduction

Conclusions

References

Tables

Figures

14

$>1$

4

Back

Close

Full Screen / Esc

Printer-friendly Version

Interactive Discussion

(c) (i) 

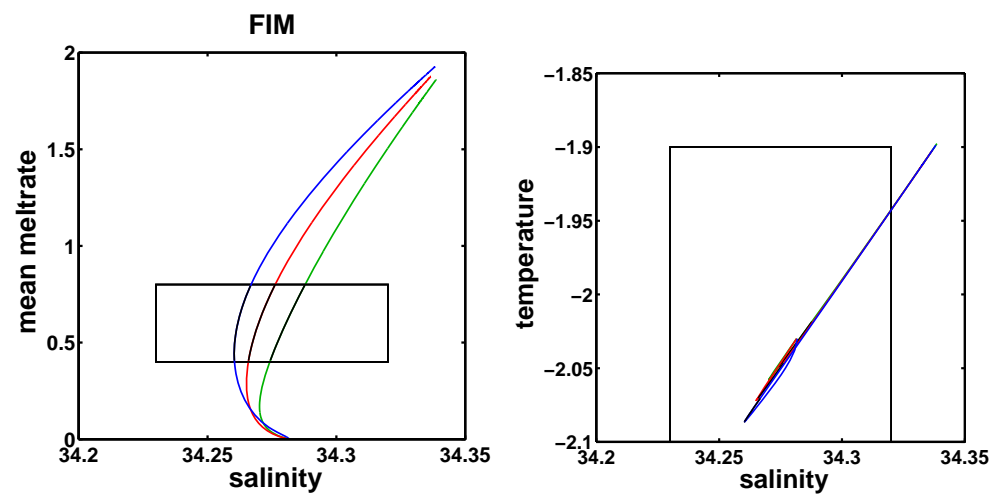

\section{TCD}

8, 919-951, 2014

Antarctic ice shelf caverns

D. Olbers et al.

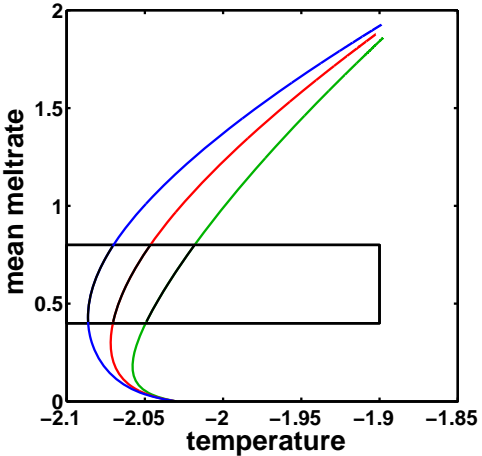

Title Page

Abstract

Conclusions

Tables

14

4

Back

\section{Full Screen / Esc}

Printer-friendly Version

Interactive Discussion

Fig. 9. Same as Fig. 7 but for Fimbulisen (FIM).

Introduction

References

Figures

$>$

Close 

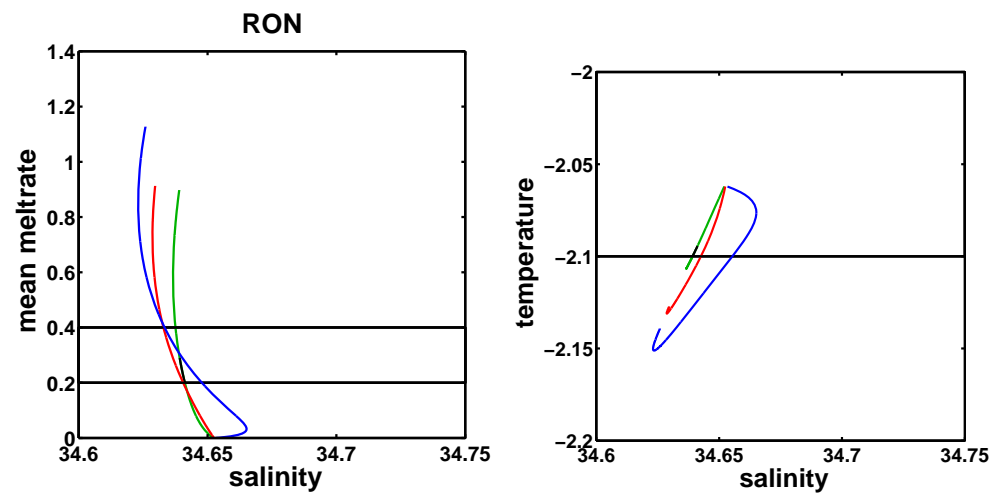

TCD

8, 919-951, 2014

Antarctic ice shelf caverns

D. Olbers et al.

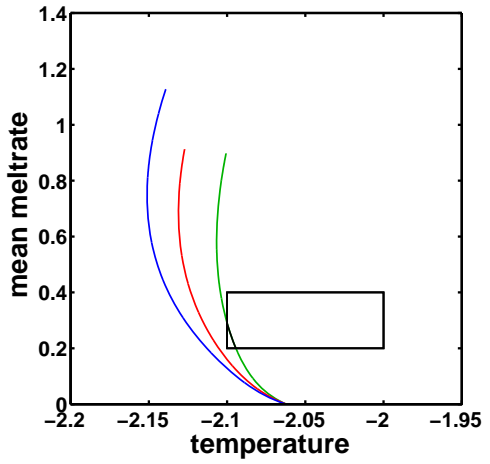

Title Page

Abstract

Conclusions

Tables

14

4

Back

Full Screen / Esc

Printer-friendly Version

Interactive Discussion

Fig. 10. Same as Fig. 7 but for Ronne Ice Shelf (RON).

\section{Introduction}

References

Figures

$\Delta$

$>$

Close

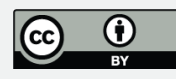



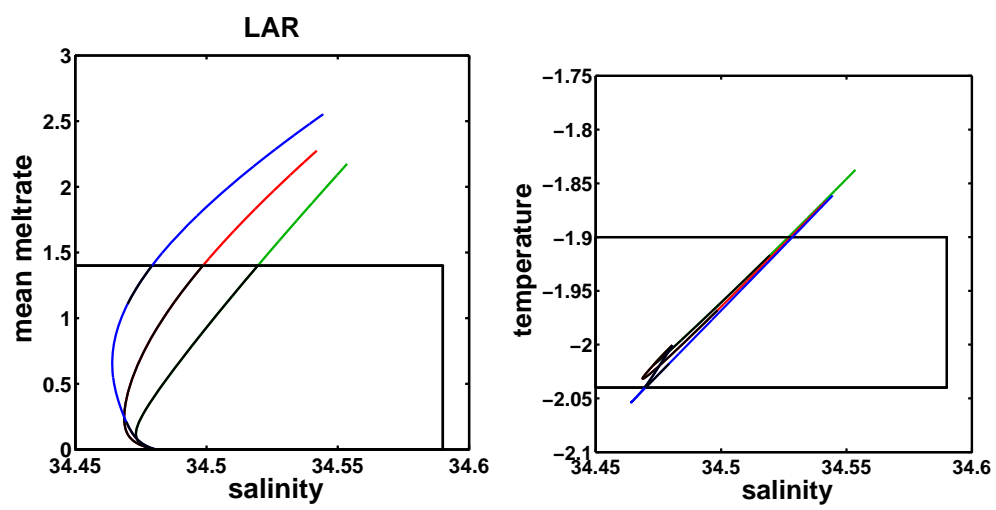

TCD

8, 919-951, 2014

Antarctic ice shelf caverns

D. Olbers et al.

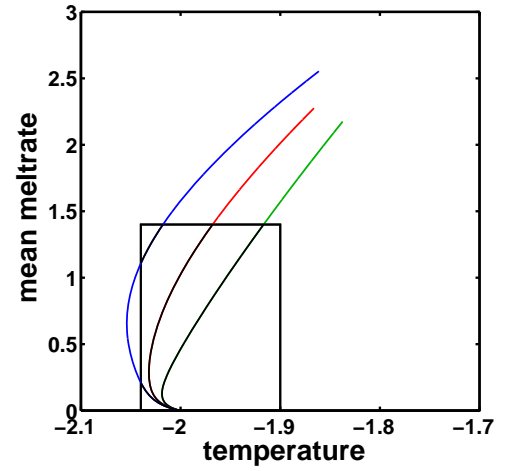

4

\section{Full Screen / Esc}

Fig. 11. Same as Fig. 7 but for Larsen C Ice Shelf (LAR). 

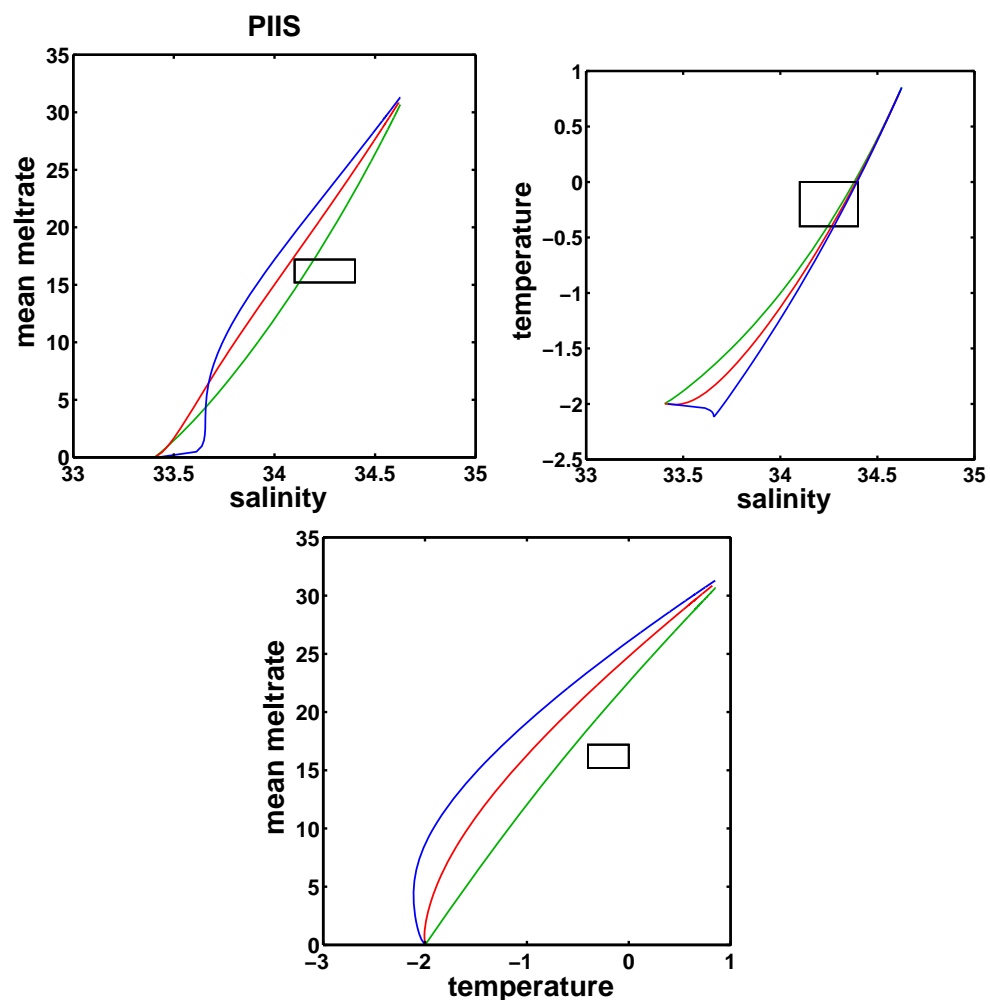

TCD

8, 919-951, 2014

Antarctic ice shelf caverns

D. Olbers et al.

Title Page

4

Full Screen / Esc

Fig. 12. Same as Fig. 7 but for Pine Island Ice Shelf (PIIS). 

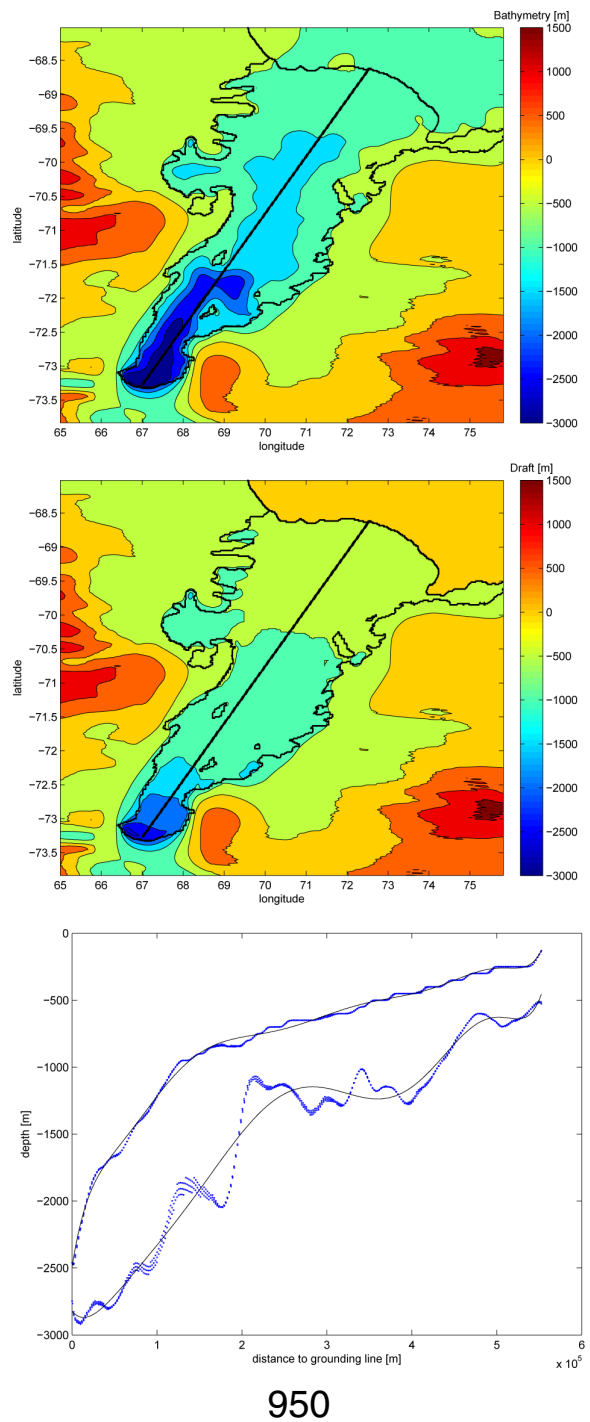

\section{TCD}

8, 919-951, 2014

Antarctic ice shelf caverns

D. Olbers et al.

Title Page

\begin{tabular}{|c|c|}
\hline Abstract & Introduction \\
\hline Conclusions & References \\
\hline Tables & Figures \\
\hline I4 & $\triangleright$ I \\
\hline 4 & $\triangleright$ \\
\hline Back & Close \\
\hline
\end{tabular}

Full Screen / Esc

Printer-friendly Version

Interactive Discussion 
Fig. 13. Bathymetry (upper) and draft (middle) of the AMY cavern. The black straight line is the Center Line (CL). Bathymetry and draft along $C L$ and the fit was derived with a 9th-degree polynomial (lower). The data is retrieved from RTOPO-1 (Timmermann et al., 2010).

\section{TCD}

8, 919-951, 2014

\section{Antarctic ice shelf} caverns

D. Olbers et al.

Title Page

Abstract Introduction

Conclusions

References

Tables

Figures

14

$>$ I

4

Back

Close

Full Screen / Esc

Printer-friendly Version

Interactive Discussion 